\title{
La filosofia com a ciència teòrica: la proposta de Timothy Williamson
}

\author{
Manel Pau \\ Investigador independent \\ manelpau@gmail.com
}

\section{Resum}

Timothy Williamson defensa que la filosofia és una ciència teòrica que s'ocupa d'investigar sobre la realitat, d'obtenir coneixement, i que ho fa construint teories, confrontant-les amb l'evidència, d'una manera sistemàtica, disciplinada i socialment organitzada, com les altres ciències. En aquest article es compara aquesta posició, d'una banda, amb la que considera que la filosofia és una reflexió de segon ordre sobre la ciència, la moral, la política, l'art...; i, de l'altra, amb la concepció de la filosofia com a guia de la vida, com a recerca de la saviesa pràctica.

Paraules clau: Timothy Williamson; filosofia de la filosofia; reflexió de segon ordre; saviesa pràctica

\section{Abstract. Philosophy as a theoretical science: Timothy Williamson's proposal}

Timothy Williamson argues that philosophy is a theoretical science that deals with researching reality and obtaining knowledge, and that it does so by constructing theories and confronting them with evidence, in a systematic, disciplined and socially organised way, like the other sciences. This article compares this position, on the one hand, with the view that considers philosophy to be a second-order reflection on science, morality, politics, art etc.; and also, with the conception of philosophy as a guide to life, a search for practical wisdom.

Keywords: Timothy Williamson; philosophy of philosophy; second-order reflection; practical wisdom

\section{Sumari}

1. La filosofia com a reflexió de segon ordre

3. Conclusions

Referències bibliogràfiques

2. La filosofia com a guia de vida 
La filosofia és una ciència teòrica. Aquesta és la contundent i provocativa afirmació que fa Timothy Williamson en un llibre recent destinat a un públic ampli, no especialitzat (2018). Com l'hem d'entendre? En primer lloc, és evident que la filosofia no és una ciència natural com la biologia, la física, la química o l'astronomia. No s'ocupa de fer experiments o observacions del món físic. Però també hi ha ciències socials, no només ciències naturals. I, finalment, la matemàtica també és una ciència, tot i que no sigui una ciència empírica, és a dir, no investiga directament sobre la realitat física o social. Per tant, la ciència abastaria les ciències formals (la matemàtica i la lògica), les ciències naturals i les ciències socials, si entenem que totes representen una recerca de coneixement sobre la realitat, sistemàtica, organitzada socialment i que construeix teories basades en l'evidència, malgrat que cadascuna pugui tenir les seves especificitats i els seus mètodes particulars, i encara que el grau de maduresa de cada ciència sigui diferent, precisament perquè les ciències són productes històrics, contingents, que s'han de veure més aviat com a tradicions d'investigació. És en aquest esquema on hi hauria lloc per encabir-hi també la filosofia.

Si la matemàtica és una ciència, encara que sigui una ciència teòrica, una activitat que es fa en una butaca, de paper i llapis (o d'ordinador), la filosofia, que és clarament una activitat de butaca, pot ser també una ciència. Afirmar que la filosofia és una ciència és afirmar que s'ocupa d'investigar sobre la realitat, d'obtenir coneixement, i que ho fa construint teories, confrontant-les amb l'evidència, d'una manera sistemàtica, disciplinada i socialment organitzada, com les altres ciències.

Els conceptes matemàtics sorgeixen de l'experiència humana general, de les operacions de comptar, de l'experiència amb l'espai físic... I a la vegada són part constitutiva de les teories científiques empíriques més madures. Dins del continu de la recerca de coneixement, la matemàtica s'especialitza en unes qüestions molt generals basades en la forma, en l'abstracció... La filosofia s'ocupa de temes encara més generals i abstractes que tradicionalment s'han agrupat en tres branques principals: la teoria del coneixement, la metafísica i la filosofia pràctica (moral i política).

Aquesta manera de concebre la filosofia implica una sèrie de conseqüències i xoca amb altres concepcions, almenys aparentment. D'una banda, amb les que emfasitzen el caràcter metateòric i crític de la filosofia i, de l'altra, amb les que l'acosten a la recerca de la saviesa. Tot seguit examinarem aquests contrastos.

\section{La filosofia com a reflexió de segon ordre}

Una posició molt estesa és la que considera que la filosofia no és un saber substantiu, sinó una reflexió — una anàlisi i una crítica — sobre els fonaments, els mètodes, els pressupòsits, els resultats, les conseqüències... de les diferents ciències i de les pràctiques tècniques, artístiques, morals o polítiques. Una activitat teòrica de segon ordre. La filosofia seria sobretot filosofia de X: filosofia de la ciència (filosofia de la física, de la química, de la biologia...), filosofia 
de la matemàtica o de la lògica. I més enllà de les ciències naturals, filosofia de la moral, del dret, de la política, de les arts... Una investigació que no busca un saber superior allunyat del saber ordinari, ni del científic, ni del pràctic, sinó que representa un grau en l'abstracció, una reflexió en els límits. A casa nostra això és el que algunes generacions vam veure en l'opuscle de Manuel Sacristán sobre el lloc que ocupa la filosofia en els estudis superiors (1968): no hi ha filosofia sinó filosofar. Fins i tot, deia Sacristán, acadèmicament la filosofia hauria d'anar al final, després d'una activitat científica o pràctica. Desconfiança, doncs, en el filòsof tradicional davant del científic, l'artista o el polític reflexius.

Aquesta posició propugna una continuïtat entre la ciència i la filosofia en dos sentits. D'una banda, es valora la ciència com el millor coneixement de la realitat disponible en cada moment històric, i, per tant, qualsevol elaboració filosòfica hauria de partir dels resultats científics. I, d'una altra, s'adopten uns hàbits intel-lectuals acostats als de la ciència (afany per la claredat, per les formulacions explícites, per utilitzar mètodes analítics i eines formals...). Tot i això, la recerca científica i la reflexió filosòfica es mantenen separades. Així, una mateixa persona pot ser a la vegada especialista en biologia teòrica i filòsof de la biologia, però en principi es pot distingir entre el que és un resultat científic positiu, establert segons els cànons vigents en la disciplina, i el que és reflexió metateòrica sobre el sentit, la metodologia o la contextualització social i històrica d'aquest resultat.

La proposta que fa Williamson -iniciada d'una manera més tècnica en el seu llibre sobre la filosofia de la filosofia (2007) — no s'aparta d'aquesta tradició en termes generals, però podríem dir que fa un pas més enllà. Admetent que la filosofia s'ocupa d'aquesta reflexió metacientífica, considera que els seus resultats constitueixen un saber substantiu. Aquí apareix de nou la comparació amb la matemàtica. La matemàtica manté una continuïtat amb el conjunt de les ciències, tant pel que fa a les motivacions com a les aplicacions, però no hi ha dubte que obté veritats substantives sobre els objectes matemàtics (sigui el que sigui l'estatut metafísic que tinguin aquests objectes). D'una manera semblant, la filosofia és una recerca per aconseguir coneixement sobre certs aspectes de la realitat: aquells que clàssicament s'inclouen en la metafísica, l'epistemologia i la filosofia moral i política (la pregunta sobre com hem de viure). Per exemple, en el cas de la metafísica volem dir qüestions molt generals i abstractes com ara la possibilitat, la necessitat, la contingència... Aquí el punt de discrepància amb altres concepcions és que per a algunes persones la filosofia estaria més interessada en la pregunta que no pas en la resposta. És a dir, la filosofia seria una sèrie recurrent de preguntes que es van reformulant al llarg de la història, sense que hi hagi un sentit clar de progrés. Des d'aquest punt de vista, quan un problema es resol d'una manera més o menys concloent deixa de ser una qüestió filosòfica i la solució que se'n deriva passa a ser un saber científic. Això correspon a la imatge tradicional de les diverses ciències com a branques que van sorgint en diferents períodes del tronc comú de la filosofia (de la recerca general del coneixement). 


\section{La filosofia com a guia de vida}

En l'altre extrem ens trobem amb la filosofia entesa com una guia de la vida, com una saviesa. Evidentment aquesta és una concepció que té una tradició molt llarga. Martha Nussbaum, en els seus llibres sobre la fortuna (1986) i sobre la teràpia del desig (1994), exposa com aquesta concepció és present en el pensament grec. Insistint que el que té de distintiu la filosofia és la importància que dona a l'examen racional, a la deliberació racional, com a ajuda al bon viure, en contrast amb altres teràpies o tècniques de transformació personal que es dirigeixen més directament a les emocions o als canvis a través del condicionament.

Però també hi són propers filòsofs actuals de diverses orientacions. Per exemple, Robert Nozick — que entre nosaltres gairebé només se cita en relació amb les seves tesis llibertarianes - ha escrit sobre la saviesa i sobre la filosofia com a manera de viure (1989).

Un professional (un científic, un metge, un artesà...) savi és una persona que té un coneixement global i profund del seu ofici, una persona que sap discernir entre el que és important i el que no ho és. Una persona sàvia en sentit ètic és la que sap el que és important per portar una bona vida.

És un fet que es pot ser feliç (viure una bona vida) sense ser savi. No solament per la fortuna. És a dir, perquè les circumstàncies externes ens porten a una vida feliç. També pot ser que sapiguem viure bé sense ser-ne conscients. Que els mecanismes psicològics que ens porten a prendre les decisions correctes en relació amb el fet de portar una bona vida no siguin accessibles a la consciència. I encara pot ser que en siguem parcialment conscients però que no siguem capaços de formular explícitament i en forma de saber comunicable quins són els criteris que guien la nostra vida (bona).

Per a Nozick, la filosofia pot ser una via cap al bon viure. No diu que sigui l'única: n'hi pot haver d'altres. La via de la filosofia és la que es basa en la saviesa i a la vegada considera la mateixa saviesa —una existència examinada i autodirigida - com un component intrínsec de la bona vida.

En canvi, Williamson no presenta la filosofia com una saviesa o com una guia per a la vida, sinó com una disciplina acadèmica. En principi, un filòsof professional pot viure de la manera que li sembli. En això no és diferent d'un matemàtic o d'un biòleg o d'un metge. La dedicació a la filosofia no implica un compromís amb una forma determinada de vida. Ara bé: els plans de vida, personals o col-lectius, les ideologies, les concepcions del món, les reflexions sobre el valor, el sentit de l'existència... tenen un component de reflexivitat i de recerca de les arrels, de profunditat, que certament l'acosten a la filosofia entesa com a disciplina de recerca. En tot cas, podem dir que no és d'això del que ens vol parlar aquest llibre. 


\section{Conclusions}

En primer lloc, ens podem plantejar la qüestió dels noms. Sembla clar que pot ser útil reservar el nom ciència per a les recerques que ordinàriament anomenem així. Encara que considerem que la filosofia, les ciències naturals, les ciències socials, la història, les ciències formals... siguin el mateix, és a dir, que totes siguin ciència (en el sentit genèric de recerca sistemàtica i organitzada del coneixement), podem seguir mantenint els noms tradicionals. Si el que vol afirmar Williamson és que la filosofia s'assembla a les ciències per la recerca sistemàtica i rigorosa que les caracteritza i per la utilització d'alguns mètodes que també fan servir la matemàtica i la ciència empírica, això ja està contingut en el concepte de disciplina. Aleshores podríem dir simplement que la filosofia és una disciplina intel-lectual i continuar reservant la paraula ciència per referirnos a les ciències empíriques i formals, i potser, segons el context, fins i tot només per a les ciències de la natura (biologia, física, química, geologia...).

Tampoc penso que tingui sentit establir jerarquies dins de les ciències d'acord amb el significat de quina és més bàsica, o de relacions de reducció (la química es pot reduir a física o la biologia es pot reduir a bioquímica...). Més aviat caldria pensar en un pluralisme d'aproximacions a diferents aspectes de la realitat. Aproximacions que aspiren a ser mútuament no contradictòries i complementàries, encara que no sempre ho siguin en cada moment històric. Atesa la complexitat de la realitat en comparació amb les nostres capacitats cognitives, no té sentit esperar que una única ciència ho expliqui tot.

Ara bé, el principal objectiu del llibre que comento és estimular els filòsofs a fer un tipus de recerca "millor», mostrant que els mètodes de la filosofia, els mètodes que es consideren de butaca, que són els tradicionals de la filosofia, no són o poden no ser tan diferents dels mètodes de la resta de les ciències. Més concretament, dels de la matemàtica i de la ciència natural i social teòriques. Per això insisteix en la importància dels experiments mentals, de la inferència a la millor explicació, de la construcció de models teòrics (és a dir, del treball amb construccions idealitzades més que no pas en la recerca de lleis universals). I recalca la contraposició entre una concepció popperiana de la recerca científica, en què les teories són refutades per l'experiència, i una altra en què els models científics són la millor explicació a l'evidència disponible i en què la nova evidència que refutaria el model s'utilitza per construir-ne un de millor.

La utilització d'experiments mentals i l'anàlisi de les intuïcions no és exclusiu de la filosofia. Dintre de les ciències de la natura aquests mètodes també hi tenen un paper important. És evident que dins de la divisió del treball científic hi ha persones concentrades en l'experimentació i que són especialment hàbils en aquesta tasca, mentre que d'altres ho fan en la feina de construir models i teories. En aquest sentit, la filosofia és a prop de les especialitats teòriques de la ciència. Per això és natural que els experiments mentals, i en general l'ús de la capacitat imaginativa, hi tinguin un paper important.

De vegades hi ha la idea que la filosofia té per missió la clarificació conceptual. Es considera una actitud filosòfica la que davant la pregunta "Això és X?" 
(això és veritat, o just, o moralment correcte...) contesta amb una altra pregunta: "Què entens per X?" (què entens per veritat, o just, o moralment correcte...). L'actitud característica de la filosofia seria explorar el significat de les paraules que utilitzem en les nostres discussions, aclarir la relació entre conceptes... Williamson considera que la discussió sobre els conceptes que utilitzem per estructurar les nostres teories no és exclusiva de la filosofia, sinó que es dona en totes les ciències. La discussió sobre què s'entén per molècula, per partícula elemental o per espècie biològica no és una discussió externa a la ciència, sinó que forma part del desenvolupament de la química, la física i la biologia, respectivament. Tant en filosofia com en les ciències empíriques la reelaboració dels conceptes és una feina substantiva que té per objectiu estructurar i ampliar el coneixement.

En general, podem dir que Williamson no nega els trets que tradicionalment es consideren propis de la disciplina filosòfica, o de la recerca filosòfica. Simplement tracta de ressituar-los de tal manera que es vegi que no fan que la filosofia deixi de ser una ciència, una investigació que busca la veritat a través de les evidències. D'on venen aquestes evidències? Generalment no és el mateix filòsof qui les recull o les obté. Les evidències provenen de la resta de les ciències, del coneixement comú i de l'experiència humana en general, social, moral, política... És en aquest sentit que el coneixement de la filosofia forma un continu amb el de la resta de les ciències i dels sabers pràctics.

El punt en què Williamson s'aparta d'algunes de les variants de la concepció de la filosofia com a reflexió metateòrica és en la reivindicació de l'existència d'un saber filosòfic substantiu. És a dir, de teories filosòfiques correctes en el mateix sentit que una teoria científica natural pot ser-ho. De teories que són una aproximació revisable, històricament situada, fal.lible, temptativa... - i totes les altres precaucions que hi vulgueu afegir - a la veritat. Per a ell la filosofia progressa. Per a d'altres, en canvi, només hi ha progrés quan deixa de ser filosofia.

El que queda fora d'aquesta visió és la consideració de la filosofia com a art de viure, però que en quedi fora no vol dir que les dues aproximacions siguin incompatibles. Williamson està parlant de la disciplina professional, acadèmica, però no s'exclou que per a molta gent, siguin filòsofs professionals o no, la pregunta sobre la bona vida humana sigui central. Un enfocament naturalista, precisament, ens porta a pensar que la raó és única. És la mateixa raó la que ens fa fer ciència i la que ens guia en la vida. Per tant, també podem anomenar filosofia aquesta recerca de la saviesa pràctica en la mesura en què es basa en la reflexió i en l'argumentació racional més que no pas en altres aproximacions religioses, místiques o estètiques. El filòsof aspira a fer que aquesta saviesa sigui explícita, que esdevingui un coneixement comunicable, que es pugui ensenyar i aprendre. 


\section{Referències bibliogràfiques}

Nozick, Robert (1989). Examined life: Philosophical meditations. Nova York: Touchstone. Versió en castellà: Meditaciones sobre la vida. Traducció de Carlos Gardini. Barcelona: Gedisa, 1992.

Nussbaum, Martha C. (1986). The Fragility of goodness: Luck and ethics in Greek tragedy and philosophy. Cambridge: Cambridge University Press. Versió en castellà: La fragilidad del bien: Fortuna y ética en la tragedia y la filosofía griega. Traducció d'Antonio Ballesteros. Madrid: Visor, 1995.

- (1994). The therapy of desire: Theory and practice in hellenistic ethics. Princeton, NJ: Princeton University Press. Versió en castellà: La terapia del deseo: Teoría y práctica de la ética helenistica. Traducció de Miguel Candel. Barcelona: Paidós, 2003.

SACRISTÁN, Manuel (1968). Sobre el lugar de la filosofía en los estudios superiores. Barcelona: Nova Terra. Recollit a Papeles de filosofia. Barcelona: Icaria, 1984.

Williamson, Timothy (2007). The philosophy of philosophy. Malden, MA: Blackwell.

- (2018). Doing philosophy: From common curiosity to logical reasoning. Oxford: Oxford University Press. Publicat de nou amb el títol Philosophical method: A very short introduction. Oxford: Oxford University Press, 2020.

Manel Pau és investigador en temes de filosofia moral i política de la ciència i la tècnica. Doctor per la Universitat de Barcelona dins del programa «Ciutadania i Drets Humans». Llicenciat en Química.

Manel Pau is a researcher in moral and political philosophy of science and technology. He has a PhD from the University of Barcelona within the "Citizenship and Human Rights" programme and a degree in Chemistry. 